\title{
Systematic review and meta-analysis: $\alpha$-adrenergic receptor blockers in chronic prostatitis
}

\author{
Wanqin Deng", Xianqun Du*, Wanzhen Zhou", Xuefeng Mei, Ying Tian, Lan Chen, Yuguo Xia, \\ Ou Zhang
}

Department of Urology Surgery, Hospital of Chengdu University of Traditional Chinese Medicine, Chengdu, China

Contributions: (I) Conception and design: W Deng, X Du, W Zhou; (II) Administrative support: X Mei, Y Tian; (III) Provision of study materials or patients: W Deng, X Du, W Zhou, L Chen, O Zhang, Y Xia; (IV) Collection and assembly of data: All authors; (V) Data analysis and interpretation: W Deng, X Mei, Y Tian, L Chen, O Zhang, Y Xia; (VI) Manuscript writing: All authors; (VII) Final approval of manuscript: All authors.

\#These authors contributed equally to this work.

Correspondence to: Ou Zhang; Yuguo Xia. Department of Urology Surgery, Hospital of Chengdu University of Traditional Chinese Medicine, No. 39 Shierqiao Road, Chengdu 610072, China. Email: Zhangou0609@163.com; doctorxiayuguo@163.com.

\begin{abstract}
Background: Prostatitis seriously endangers the health of men. While they have been widely used in recent years, there remains a lack of systematic evaluation of the clinical efficacy of $\alpha$-receptor blockers $(\alpha$-RBs $) / \alpha$-adrenergic receptor blockers $(\alpha$-ARBs) in its treatment. Based on this, this study was developed to systematically evaluate the clinical effect of $\alpha$-ARB in the treatment of prostatitis.

Methods: Randomized controlled trials (RCTs) studying $\alpha$-RBs or $\alpha$-ARBs, placebos, or other measures to treat prostatitis were searched in Cochrane Library, PubMed, Embase, and CBM databases from establishment to December 2020. The quality of included articles was evaluated using the Cochrane System Review Manual and Jadad tools, and a meta-analysis was performed using Review Manager 5.3 software.
\end{abstract}

Results: A total of six articles meeting the requirements were found and included 450 patients. Metaanalysis showed that the National Institutes of Health Chronic Prostatitis Symptom Index (NIH-CPSI) score [mean difference $(\mathrm{MD})=-1.76,95 \%$ confidence interval $(\mathrm{CI})$ : $(-3.35$ to -0.17$)$, and $\mathrm{P}=0.03$ ], pain score $[\mathrm{MD}=-2.24,95 \% \mathrm{CI}:(-3.65$ to -0.83$)$, and $\mathrm{P}=0.002]$, voiding symptom score $[\mathrm{MD}=-1.21,95 \% \mathrm{CI}:(-2.06$ to -0.35$)$, and $\mathrm{P}=0.006]$, and quality of life score $[\mathrm{MD}=-1.40,95 \% \mathrm{CI}:(-1.48$ to -1.33$)$, and $\mathrm{P}<0.00001]$ for patients in the experimental group were lower in contrast to those in the control group after the treatment.

Discussion: The use of $\alpha$-ARB could significantly improve the treatment effect of patients with prostatitis and improve their quality of life.

Keywords: $\alpha$-adrenergic receptor blockers ( $\alpha$-ARBs); $\alpha$-receptor blockers ( $\alpha$-RBs); prostatitis; meta-analysis

Submitted Jul 21, 2021. Accepted for publication Sep 01, 2021.

doi: 10.21037/apm-21-2160

View this article at: https://dx.doi.org/10.21037/apm-21-2160

\section{Introduction}

Prostatitis is a urological disease characterized by a complicated etiology and recurrent course. As it is difficult to treat and relapses are frequent, the disease seriously affects the quality of life of patients $(1,2)$. Type III prostatitis is also referred to as pelvic floor chronic pain syndrome or non-bacterial chronic prostatitis (CP), and accounts for the largest proportion $(90 \%)$ of prostatitis cases $(3,4)$, and at present, there is no uniform standard its treatment in clinical practice.

The excitability of the bladder neck, urethra, and smooth muscle of the prostate can be selectively inhibited by $\alpha$-adrenergic receptor blockers ( $\alpha$-ARBs), which can reduce the obstruction of the position of the urethra by promoting muscle relaxation and alleviating urethral obstruction $(5,6)$. In recent years, the effects of $\alpha$-ARBs such as alfurazosin, tamsulosin, and terazosin in the treatment of type III 
prostatitis has been confirmed by many domestic and foreign scholars (7-9). However, current clinical studies on the treatment of CP with $\alpha$-ARBs have different results and are of varying quality, using different scales and measuring different effects.

Therefore, we conducted a meta-analysis to evaluate the clinical effect of $\alpha-\mathrm{ARBs}$ in the treatment of $\mathrm{CP}$, providing medical evidence for clinical treatment. We present the following article in accordance with the PRISMA reporting checklist (available at https://dx.doi. org/10.21037/apm-21-2160).

\section{Methods}

\section{Inclusion and exclusion criteria}

The inclusion criteria were defined as follows: articles which were randomized controlled trials (RCTs) on the treatment of prostatitis with $\alpha$-ARBs (references in the included articles had to be traced in both English or Chinese); articles in which the research objects complied with the diagnostic criteria for prostatitis issued by the National Institutes of Health (NIH) and were diagnosed as prostatitis patients after testing; articles which compared the treatment effects of $\alpha$-ARBs and placebo or other treatment measures; and articles which mentioned outcome observation indicators including the National Institutes of Health Chronic Prostatitis Symptom index (NIH-CPSI) score, pain score, voiding symptom score, and quality of life score.

The exclusion criteria were as follows: articles including patients with disease such as urinary system infections, genital herpes, or urinary tract strictures; articles with patients with a history of prostate or bladder surgery; articles including patients who were treated with other similar drugs during treatment; articles which were non-original research reports, including review studies, meta-analysis research, treatment experience summary research, case report studies or animal experiment studies; articles without control groups or with incomparable samples in different groups; and articles which included patients with incomplete information and results data.

\section{Retrieval strategy}

In accordance with the search strategy formulated by the Cochrane Collaboration Work Manual, the articles were searched in The Cochrane Library, PubMed, Embase, and CBM databases, and the related references and journal papers of the included articles were tracked. The search parameters were set from establishment to December 2020, and the search language was not limited. The English search terms were limited to "prostatitis", "chronic prostatitis", " $\alpha$-antagonists", “ $\alpha$ receptor antagonist”, “ $\alpha$ adrenergic antagonists", or " $\alpha$ blocker".

\section{Article retrieval and quality evaluation}

Two researchers independently read the full text of the articles and extracted relevant information, with disagreements or disputes resolved through discussion or the assistance of a third researcher. The quality of the included articles was evaluated using Jadad, and the evaluation content included whether: the article was an RCT; the random method used was appropriate; the study was a double-blind test; the applied double-blind method was appropriate; and whether there was loss of follow-up or withdrawal of the patients, whether the reason was explained, and whether the intentional analysis method was adopted. "Yes" attracted 1 point, "No" attracted 0 points, and the total score was 5 points. If the total score was less than 2 , it indicated the article was of low quality, and if the total score was greater than 2, the article was considered high-quality.

The Cochrane Reviewer's Handbook version 4.2.5 was then used to evaluate the quality of the articles. The evaluation content included whether it was a randomized trial; whether there was an allocation hiding; whether a blind test was used; whether the result data was complete; whether there was selective reporting of results; and whether there was other bias.

\section{Data extraction and statistical analysis}

The data to be extracted included the trial status, including the number of study subjects, trial design, specific intervention treatment measures, research time, and outcome indicators, as well as the baseline data of patients and indicators for feedback on the quality of the study.

Review Manager 5.3 software provided by the Cochrane Collaboration was adopted for data statistics and analysis. The results were performed with the heterogeneity test with a test level of $\alpha=0.05$, and the Peto method was used to analyze the heterogeneity of the articles. When $\mathrm{I}^{2}<50 \%$, it was considered there was no heterogeneity among the articles, and the fixed effects model (FEM) could be used for analysis, and when $\mathrm{I}^{2}>50 \%$, the articles were considered to be heterogeneous, and the random effects model 


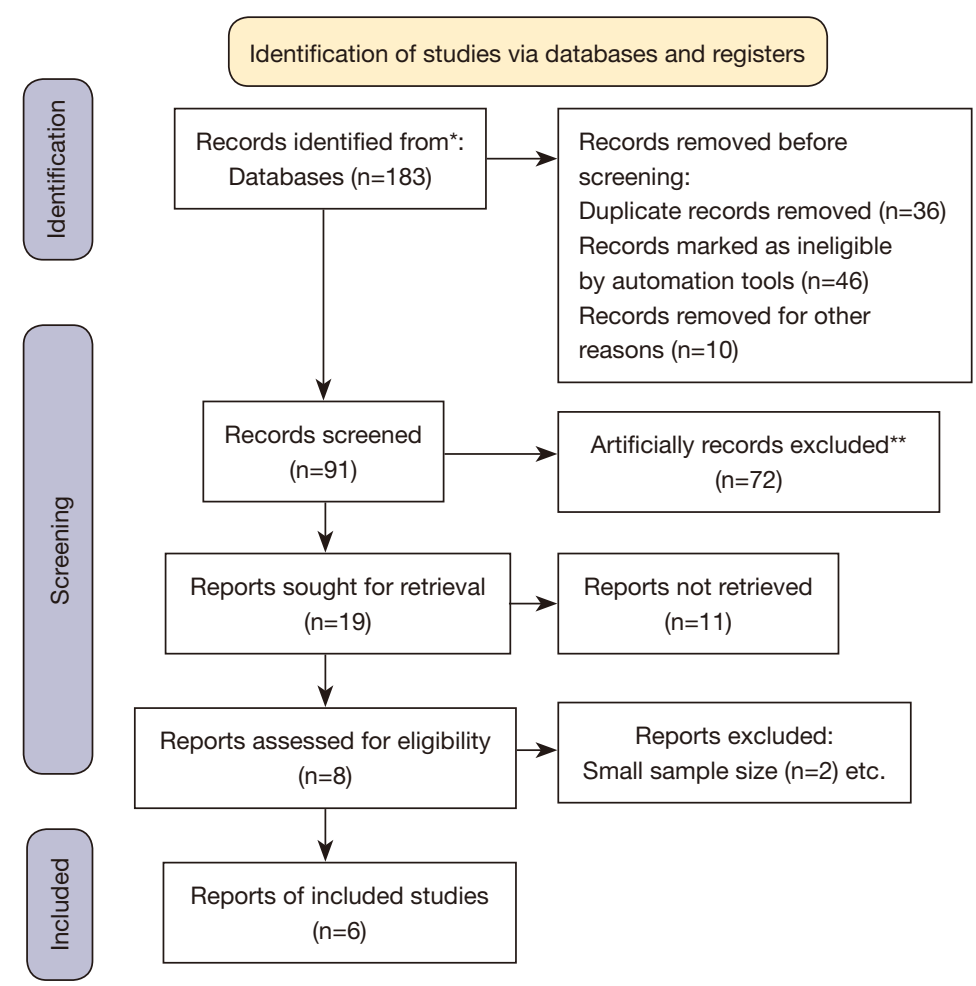

*, consider, if feasible to do so, reporting the number of records identified from each database or register searched (rather than the total number across all databases/registers).

**, if automation tools were used, indicate how many records were excluded by a human and how many were excluded by automation tools.

From: Page MJ, McKenzie JE, Bossuyt PM, et al. The PRISMA 2020 statement: an updated guideline for reporting systematic reviews. BMJ 2021;372:n71.

For more information, visit: http://www.prisma-statement.org/

Figure 1 The article retrieval process. RCTs, randomized controlled trials.

(REM) could be adopted. Results of the measurement data using the same measurement unit were expressed in weighted mean difference (WMD), otherwise they were expressed in standard mean difference (SMD). The count data results were expressed in relative risk (RR), and all results were expressed in $95 \%$ confidence interval (CI). A funnel chart was drawn to evaluate the publication bias and the concentration of the articles to the center line, and a sensitivity analysis was performed to evaluate the reliability and stability of the results.

\section{Results}

\section{Article retrieval and data extraction}

A total of 183 articles were retrieved from the database, and after the duplicated articles were deleted, 91 with certain relevance to this study were obtained. After two researchers then read the abstract of the articles and screened according to the inclusion and exclusion criteria established in the previous period, 19 full-text articles remained. After the articles with non-random type, repeated publication, and unavailable data, were removed, six articles that met the requirements were finally obtained. The article retrieval process is shown in Figure 1, and the basic information of the included articles is shown in Table 1.

\section{Evaluation on quality of included articles}

The bias risk assessment tool recommended by the Cochrane System Review Manual was adopted to evaluate the quality of the included articles, and the results are shown in Figures 2,3. There were no random sequence generation 
Table 1 Basic information of the included articles

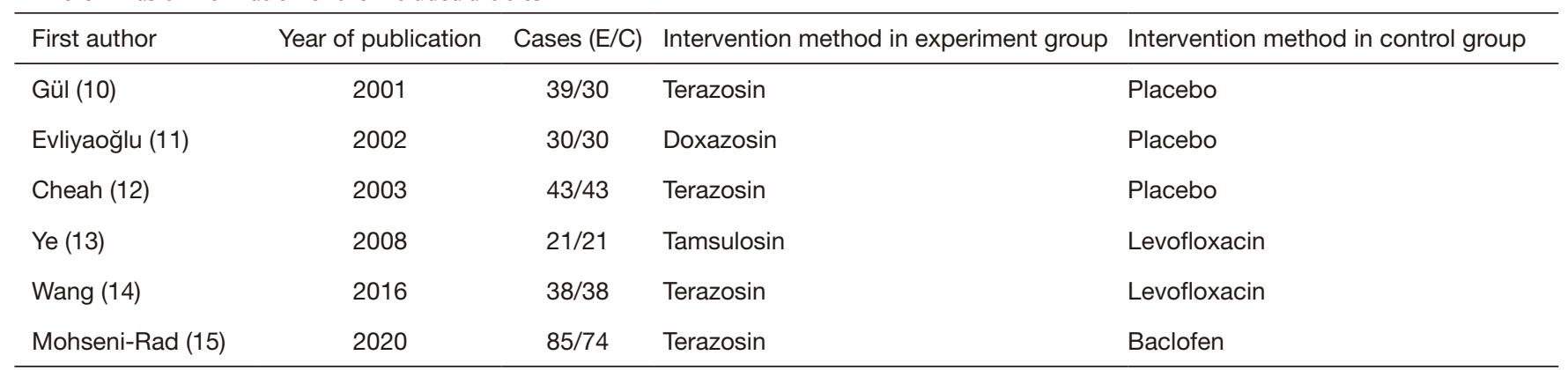

$\mathrm{E} / \mathrm{C}$, experimental group/control group.

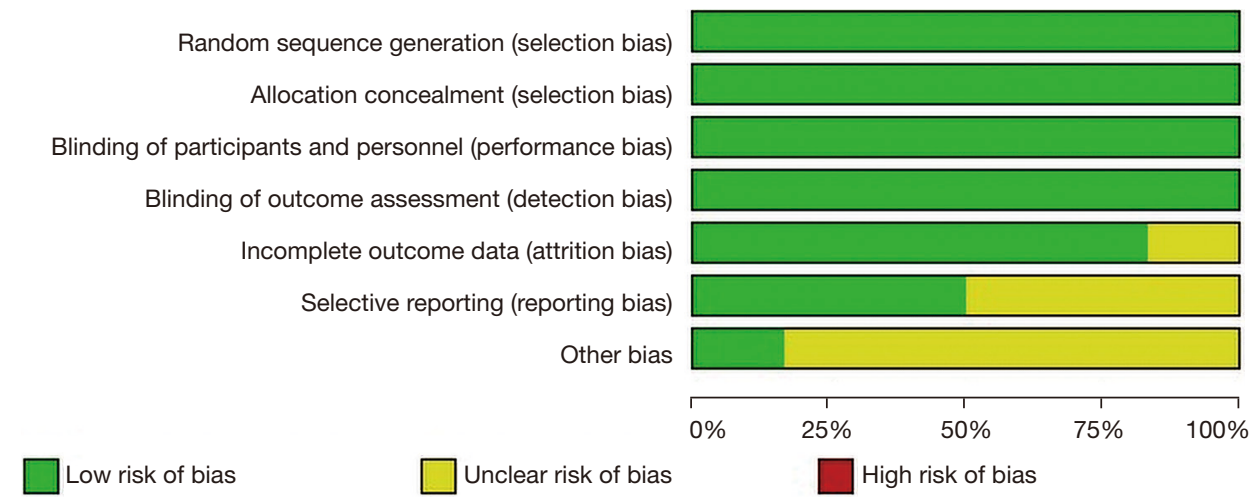

Figure 2 Bar chart for bias risk assessment of the included articles.

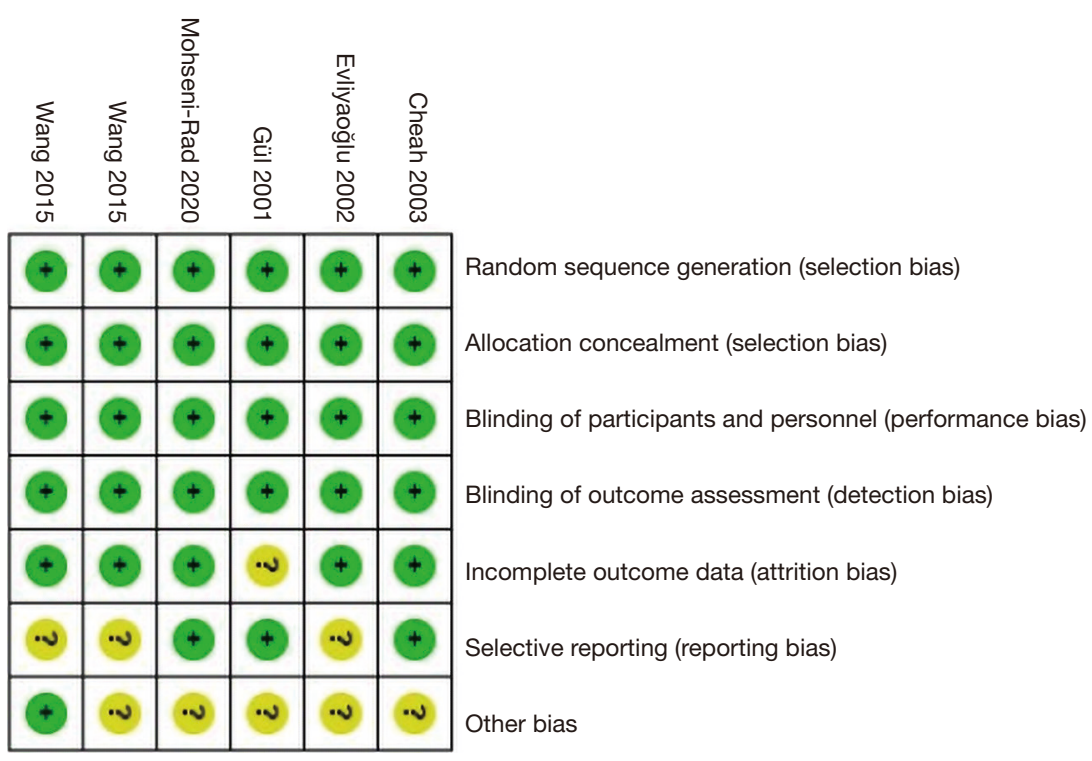

Figure 3 Assessment results of bias risk of the included articles. 
Table 2 Quality evaluation results of included articles using Jadad scale

\begin{tabular}{|c|c|c|c|c|c|c|}
\hline First author & Randomization & Binding & $\begin{array}{c}\text { Allocation } \\
\text { concealment }\end{array}$ & $\begin{array}{l}\text { Withdrawals and } \\
\text { dropouts }\end{array}$ & $\begin{array}{l}\text { Reason of dropouts } \\
\text { and withdrawals }\end{array}$ & $\begin{array}{l}\text { Jadad } \\
\text { score }\end{array}$ \\
\hline Gül & Yes & No & NMT & MT & No & 3 \\
\hline Evliyaoğlu & Yes & No & NMT & MT & Yes & 3 \\
\hline Cheah & Yes & No & NMT & MT & Yes & 3 \\
\hline Mohseni-Rad & Yes & No & NMT & MT & No & 3 \\
\hline
\end{tabular}

MT, mentioned; NMT, not mentioned.

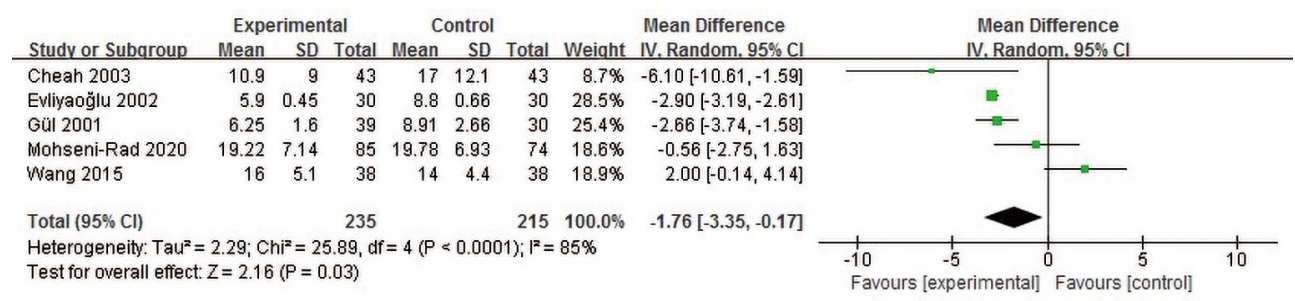

Figure 4 Forest diagram for NIH-CPSI score of patients after treatment. NIH-CPSI, National Institutes of Health Chronic Prostatitis Symptom Index.

(selection bias), allocation concealment (selection bias), of blinding of outcome assessment (detection bias) in the six articles. Except for the study of Ye et al., other articles had uncertain other bias; all had uncertain selective reporting risks except for the studies of Cheah et al., Gül et al., and Mohseni-Rad et al.; and the study of Gül et al. had the risk of incomplete outcome data. However, the overall risk of the articles included in this study was low.

The results of evaluating the quality of each included articles using the Jadad scale are shown in Table 2. It was clear that the Jadad scores of the six articles were all higher than two points, indicating they were of high quality and could meet the follow-up requirements.

\section{NIH-CPSI score}

Figure 4 illustrates the comparison and analysis results of the difference in NIH-CPSI scores between the experimental group and control group after treatment. The statistics revealed there was heterogeneity in the NIH-CPSI scores between the groups after treatment $\left(\mathrm{I}^{2}=85 \%\right.$, and $\left.\mathrm{P}<0.0001\right)$. The statistical analysis results using REM indicated that the combined effect value of the meta-analysis on the NIHCPSI total score after treatment between the two groups showed mean difference $(M D)=-1.76$ and $95 \%$ CI: $(-3.35$ to -0.17 ), and $Z=2.16$ and $P=0.03$. In summary, the NIHCPSI score after treatment in the experimental group was much lower in contrast to that in the control group, and the difference was statistically significant $(\mathrm{P}<0.05)$.

\section{Pain score}

Figure 5 illustrates the comparison and analysis results of the difference in pain score between the experimental group and the control group after treatment. The statistics revealed that there was heterogeneity in the pain score between the groups after treatment $\left(\mathrm{I}^{2}=79 \%\right.$, and $\left.\mathrm{P}=0.008\right)$. The statistical analysis results using REM indicated that the combined effect value of the meta-analysis on the pain score after treatment between the two groups showed $M D=-2.24$ and $95 \%$ CI: $(-3.65$ to -0.83$)$, and $Z=3.11$ and $P=0.002$. In summary, the pain score after treatment in the experimental group was much lower in contrast to that in the control group, and the difference was statistically significant 


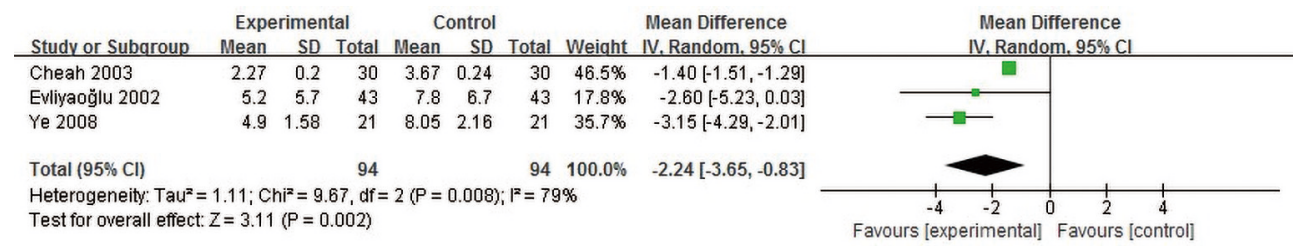

Figure 5 Forest diagram for pain score of patients after treatment.

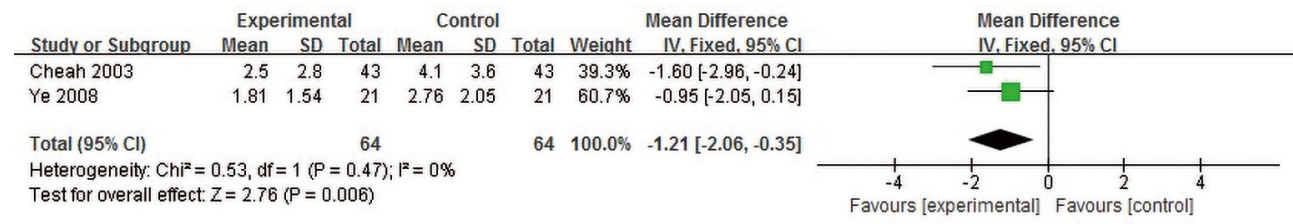

Figure 6 Forest diagram for voiding symptom score of patients after treatment.

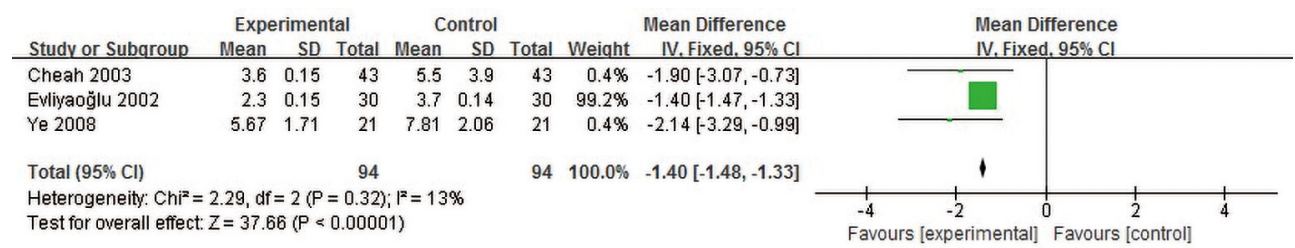

Figure 7 Forest diagram for quality of life score of patients after treatment.

$(\mathrm{P}<0.05)$.

\section{Voiding symptom score}

The difference in voiding symptom score between the experimental group and the control group after treatment was compared and analyzed, and the results are given in Figure 6. The statistics revealed that there was no heterogeneity in the voiding symptom score between the groups after treatment $\left(\mathrm{I}^{2}=0 \%\right.$, and $\left.\mathrm{P}=0.47\right)$. The statistical analysis results using FEM indicated that the combined effect value of the metaanalysis on the voiding symptom score after treatment between the two groups showed $M D=-1.21$ and $95 \%$ CI: ( -2.06 to -0.35 ), and $Z=2.76$ and $P=0.006$. In summary, the pain score after treatment in the experimental group was much lower in contrast to that in the control group, and the difference was statistically significant $(\mathrm{P}<0.05)$.

\section{Quality of life score}

The difference in quality of life score between the experimental group and the control group after treatment was compared and analyzed, and the results are given in Figure 7. The statistics revealed that there was no heterogeneity in the quality of life score between the groups after treatment $\left(\mathrm{I}^{2}=13 \%\right.$, and $\left.\mathrm{P}=0.32\right)$. The statistical analysis results using FEM indicated that the combined effect value of the meta-analysis on the quality of life score after treatment between the two groups showed $\mathrm{MD}=-1.40$ and 95\% CI: $(-1.48$ to -1.33$)$, and $Z=37.66$ and $P<0.00001$. In summary, the quality of life score after treatment in the experimental group was obviously lower in contrast to that in the control group, and the difference was statistically significant $(\mathrm{P}<0.05)$.

\section{Analysis on publication bias}

The publication bias of the evaluation indicators for the experimental group and control group was analyzed, including NIH-CPSI score, NIH-CPSI pain score, International Prostate Symptom Score (IPSS) score, and quality of life score. As illustrated in Figure 8, the funnel 

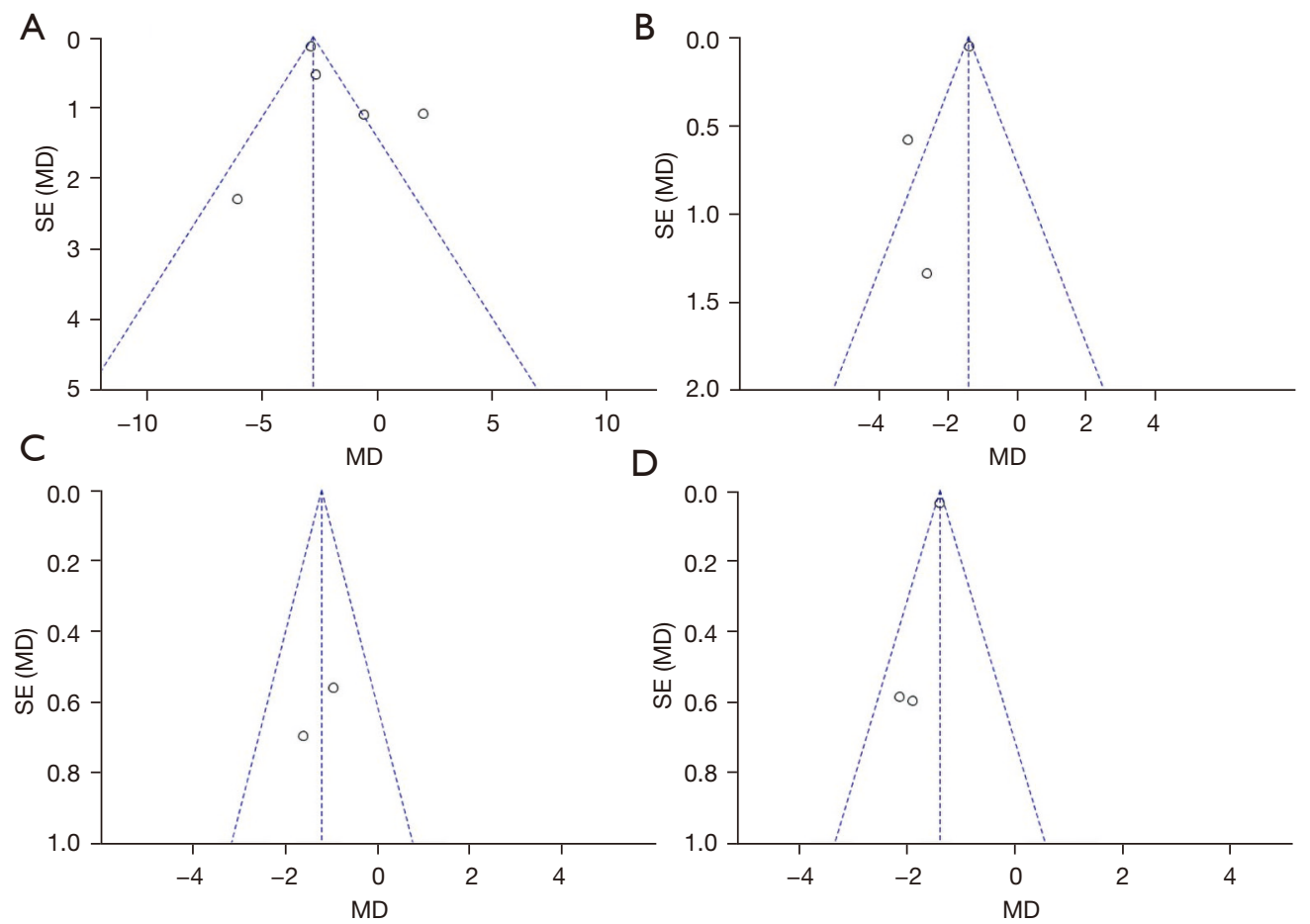

Figure 8 Funnel charts of related indicators. (A-D) The funnel charts of NIH-CPSI score, NIH-CPSI pain score, IPSS score, and quality of life score, respectively. NIH-CPSI, National Institutes of Health Chronic Prostatitis Symptom Index; IPSS, International Prostate Symptom Score.

charts of NIH-CPSI score, NIH-CPSI pain score, IPSS score, and quality of life score were more symmetrical, and the data were also more concentrated. Figure $8 A, 8 B$ show that only a few samples did not fall into the funnel charts. This indicated there was no obvious publication bias in NIH-CPSI score, NIH-CPSI pain score, IPSS score, and quality of life score for the included articles.

\section{Discussion}

Statistics show that about $50 \%$ of men will be affected by prostate syndrome (16). The clinical manifestations of CP are diverse, and quality of life of patients with this condition is similar to patients with myocardial infarction $(17,18)$. Local inflammation of the prostate, abnormal neurological function, and mental health problems can all cause the local excitability of $\alpha$ receptors. This then causes up-regulation of the expression of urethral subtype receptors, causing urine reflux to the prostate resulting in chemical infection of the prostate $(19,20)$.

About $90 \%$ of the receptors in the prostate are type $\alpha 1$ androgenic $(21,22)$ receptors, which are widely distributed in the smooth muscle of the prostate matrix, the posterior membrane of the urethral mucosa, and the capsule. Studies have shown that $\alpha 1$ receptors are one of the main factors leading to dynamic obstruction (23). Their increase causes tension of the smooth muscle of the prostate and bladder neck, further causing functional obstruction of the urethra, resulting in pain in the urinary system, abnormal urination, urinary reflux, and prostate infection. Doxazosin, Terazosin, and Tamsulosin are $\alpha$-receptor blockers $(\alpha-R B s)$ which can block $\alpha$-receptors in the urethra and bladder neck, relieve urethral spasm and pressure, thereby avoiding urinary reflux (24). Studies have shown that these drugs have highly selective blocking effects on the urethra, bladder neck, and prostate smooth muscle, and effectively treat CP (25-27).

A total of six related articles were included in this study to systematically evaluate the effect of $\alpha$-RBs in the treatment of prostatitis. Differences in the NIH-CPSI score, pain score, voiding symptom score, and quality of life score of patients with $\alpha$-RBs and placebo/other treatments were analyzed after treatment. The NIH-CPSI score is composed of three parts: a pain score, quality of life score, and voiding symptom score $(28,29)$. Clinically, a reduction in the of 
at least 4 points in the score is considered to indicate a great improvement in the patient's symptoms (30,31). The results of this study showed that the NIH-CPSI score, pain score, voiding symptom score, and quality of life score after treatment in patients treated with $\alpha$-RBs were considerably lower than those in CP patients treated with placebo/other methods.

\section{Conclusions}

The effects of $\alpha$-RBs $/ \alpha$-ARBs in the treatment of prostatitis were systematically evaluated by meta-analysis. The results showed that the use of $\alpha$-RBs could significantly reduce the NIH-CPSI and other scores of patients. This indicated $\alpha$-RBs $/ \alpha$-ARBs could improve the clinical treatment effect of patients with CP. However, the NIH-CPSI was the only outcome indicator used to evaluate treatment effects in this study. In follow-up studies, it will be necessary to continue to expand the sample size and include more outcome indicators. In short, the results of this study could provide a reference for the clinical treatment of prostatitis.

\section{Acknowledgments}

Funding: Funding for this project was received from the Affiliated Hospital of Chengdu University of Traditional Chinese Medicine (No.: 19PJ05), and Chengdu University of Traditional Chinese Medicine Affiliated Hospital "Scientific Research Ability Promotion Reserve Candidate Project Fund" (20-H20).

\section{Footnote}

Reporting Checklist: The authors have completed the PRISMA reporting checklist. Available at https://dx.doi. org/10.21037/apm-21-2160

Conflicts of Interest: All authors have completed the ICMJE uniform disclosure form (available at https://dx.doi. org/10.21037/apm-21-2160). The authors have no conflicts of interest to declare.

Ethical Statement: The authors are accountable for all aspects of the work in ensuring that questions related to the accuracy or integrity of any part of the work are appropriately investigated and resolved.

Open Access Statement: This is an Open Access article distributed in accordance with the Creative Commons Attribution-NonCommercial-NoDerivs 4.0 International License (CC BY-NC-ND 4.0), which permits the noncommercial replication and distribution of the article with the strict proviso that no changes or edits are made and the original work is properly cited (including links to both the formal publication through the relevant DOI and the license). See: https://creativecommons.org/licenses/by-nc-nd/4.0/.

\section{References}

1. Coker TJ, Dierfeldt DM. Acute bacterial prostatitis: diagnosis and management. Am Fam Physician 2016;93:114-20.

2. Qin $\mathrm{Z}, \mathrm{Wu} \mathrm{J}, \mathrm{Xu} \mathrm{C}$, et al. Long-term effects of acupuncture for chronic prostatitis/chronic pelvic pain syndrome: systematic review and single-arm meta-analyses. Ann Transl Med 2019;7:113.

3. Paterson C, Kennedy C. Pharmacological interventions for treating chronic prostatitis/chronic pelvic pain syndrome. Res Nurs Health 2020;43:548-9.

4. Morgia G, Russo GI, Urzì D, et al. A phase II, randomized, single-blinded, placebo-controlled clinical trial on the efficacy of Curcumina and Calendula suppositories for the treatment of patients with chronic prostatitis/chronic pelvic pain syndrome type III. Arch Ital Urol Androl 2017;89:110-3.

5. Darby JRT, Varcoe TJ, Holman SL, et al. The reliance on $\alpha$-adrenergic receptor stimuli for blood pressure regulation in the chronically hypoxaemic fetus is not dependent on post-ganglionic activation. J Physiol 2021;599:1307-18.

6. Hattori T, Sugaya K. Mechanisms of action for $\alpha 1$ adrenoceptor blockers in storage symptoms with new insights into the micturition reflex. Life Sci 2017;191:90-6.

7. Manjunatha R, Pundarikaksha HP, Madhusudhana HR, et al. A randomized, comparative, open-label study of efficacy and tolerability of alfuzosin, tamsulosin and silodosin in benign prostatic hyperplasia. Indian J Pharmacol 2016;48:134-40.

8. Zhao L, Tian R, Liang C, et al. Beneficial effect of tamsulosin combined with dapoxetine in management of type III prostatitis with premature ejaculation. Andrologia 2019;51:e13319.

9. Wilt TJ, Howe RW, Rutks I, et al. WITHDRAWN: Terazosin for benign prostatic hyperplasia. Cochrane Database Syst Rev 2011;(9):CD003851.

10. Gül O, Eroğlu M, Ozok U. Use of terazosine in patients with chronic pelvic pain syndrome and evaluation by 
prostatitis symptom score index. Int Urol Nephrol 2001;32:433-6.

11. Evliyaoğlu Y, Burgut R. Lower urinary tract symptoms, pain and quality of life assessment in chronic nonbacterial prostatitis patients treated with alpha-blocking agent doxazosin; versus placebo. Int Urol Nephrol 2002;34:351-6.

12. Cheah PY, Liong ML, Yuen KH, et al. Terazosin therapy for chronic prostatitis/chronic pelvic pain syndrome: a randomized, placebo controlled trial. J Urol 2003;169:592-6.

13. Ye ZQ, Lan RZ, Yang WM, et al. Tamsulosin treatment of chronic non-bacterial prostatitis. J Int Med Res 2008;36:244-52.

14. Wang J, Yan D, Liang K, et al. A randomized controlled trial of levofloxacin, terazosin, and combination therapy in patients with category III chronic prostatitis/chronic pelvic pain syndrome. Int Urol Nephrol 2016;48:13-8.

15. Mohseni-Rad H, Razzaghdoust A, Mishan MA, et al. Terazosin or baclofen in young men with chronic orchialgia: a cohort study of 499 patients. Urologia 2020;87:35-40.

16. Meng LQ, Yang FY, Wang MS, et al. Quercetin protects against chronic prostatitis in rat model through NF- $\kappa \mathrm{B}$ and MAPK signaling pathways. Prostate 2018;78:790-800.

17. Polackwich AS, Shoskes DA. Chronic prostatitis/chronic pelvic pain syndrome: a review of evaluation and therapy. Prostate Cancer Prostatic Dis 2016;19:132-8.

18. Magistro G, Wagenlehner FM, Grabe M, et al. Contemporary management of chronic prostatitis/chronic pelvic pain syndrome. Eur Urol 2016;69:286-97.

19. Appiya Santharam M, Khan FU, Naveed M, et al. Interventions to chronic prostatitis/Chronic pelvic pain syndrome treatment. Where are we standing and what's next? Eur J Pharmacol 2019;857:172429.

20. Nickel JC, Touma N. $\alpha$-blockers for the treatment of chronic prostatitis/chronic pelvic pain syndrome: an update on current clinical evidence. Rev Urol 2012;14:56-64.

21. Majumdar S, Rinaldi JC, Malhotra NR, et al. Differential actions of estrogen receptor $\alpha$ and $\beta$ via nongenomic signaling in human prostate stem and progenitor cells. Endocrinology 2019;160:2692-708.

22. Wallukat G, Jandrig B, Becker NP, et al. Autoantibodies directed against $\alpha 1$-adrenergic receptor and endothelin receptor A in patients with prostate cancer. Auto Immun
Highlights 2020;11:13.

23. Pischedda A, Pirozzi Farina F, Madonia M, et al. Use of alpha1-blockers in female functional bladder neck obstruction. Urol Int 2005;74:256-61.

24. Meltzer AC, Burrows PK, Wolfson AB, et al. Effect of tamsulosin on passage of symptomatic ureteral stones: a randomized clinical trial. JAMA Intern Med 2018;178:1051-7.

25. Füllhase C, Soler R, Gratzke C, et al. Spinal effects of the fesoterodine metabolite 5-hydroxymethyl tolterodine and/or doxazosin in rats with or without partial urethral obstruction. J Urol 2010;184:783-9.

26. Haagsman AN, Kummeling A, Moes ME, et al. Comparison of terazosin and prazosin for treatment of vesico-urethral reflex dyssynergia in dogs. Vet Rec 2013;173:41.

27. Furuta A, Suzuki Y, Igarashi T, et al. Effects of combined treatment of tadalafil and tamsulosin on bladder dysfunction via the inhibition of afferent nerve activities in a rat model of bladder outlet obstruction. Int Urol Nephrol 2018;50:839-44.

28. Franco JV, Turk T, Jung JH, et al. Pharmacological interventions for treating chronic prostatitis/chronic pelvic pain syndrome. Cochrane Database Syst Rev 2019. [Epub ahead of print]. doi: 10.1002/14651858.CD012552.pub2.

29. Franco JV, Turk T, Jung JH, et al. Non-pharmacological interventions for treating chronic prostatitis/chronic pelvic pain syndrome. Cochrane Database Syst Rev 2018;5:CD012551.

30. Kildegaard D, Graugaard-Jensen C, Andersen K, et al. Danish version of the National Institutes of HealthChronic Prostatitis Symptom Index (NIH-CPSI) questionnaire: a linguistic translation, cross-cultural adaptation and test-re-test reliability study. Scand J Urol 2019;53:62-8.

31. Zhu D, Dou X, Tang L, et al. Prevalence of prostatitis-like symptoms and outcomes of NIH-CPSI in outpatients with lifelong and acquired pe: based on a large cross-sectional study in China. Biomed Res Int 2017;2017:3473796.

(English Language Editor: B. Draper)

Cite this article as: Deng W, Du X, Zhou W, Mei X, Tian Y, Chen L, Xia Y, Zhang O. Systematic review and meta-analysis: $\alpha$-adrenergic receptor blockers in chronic prostatitis. Ann Palliat Med 2021;10(9):9870-9878. doi: 10.21037/apm-21-2160 